\title{
EL RETORNO DEL ETERNO RETORNO: NOTAS SOBRE LA COPIA, LA PARTICIPACIÓN Y LA HISTORIA
}

\section{THE RETURN OF THE ETERNAL RETURN: NOTES ON THE COPY, THE PARTICIPATION AND THE HISTORY}

\author{
Ramon Sarró*
}

$\mu \dot{\prime} \mu \eta \sigma ı=\mu \varepsilon \dot{\theta} \theta \xi 1 \varsigma$

Lévy-Bruhl (Carnets, 1949)

Como Borges, cuyas originales reflexiones e intuiciones sobre la eternidad y la circularidad me parecen particularmente sugerentes, puedo decir que "yo suelo regresar eternamente al Eterno Regreso". ${ }^{1}$ Con este texto me gustaría compartir unas reflexiones sobre la temporalidad, la copia y la repetición que espero retomar en el futuro, en un proyecto en el que pretendo comparar diferentes historicidades proféticas al hilo de algunos recientes desarrollos en la antropología de la temporalidad, la transformación y la historia. Confío que mis reflexiones podrán animar el debate en este congreso, toda vez que la periferia es uno de los temas del mismo y que los tipos de religiones a los que me he dedicado en los últimos años han sido precisamente caracterizados como "cultos periféricos" en la literatura más importante del siglo $\mathrm{XX}^{2}$. En cierta manera, pretendo contrariar la tendencia excesiva a ver ciertas manifestaciones religiosas (el pentecostalismo $y$, en particular, el profetismo) como mecanismos de "ruptura total con el pasado" (para citar la famosa frase de Birgit Meyer que dio origen a un caluroso debate dentro de la ahora llamada "antropología del cris-

* Professor associado da Universidade de Oxford (Oxford/ING). E-mail: ramon.sarro@anthro.ox.ac.uk

1. Borges (1953, p. 91).

2. Por ejemplo, por I. Lewis en su influyente Ecstatic Religion: A Study of Shamanism and Spirit Possession (1971). 
tianismo", debate animado, entre muchos otros, por Joel Robbins, Mathew Engelke, Ruth Marshall etc. $)^{3}$ o como ejemplos de "innovación” cultural, y ofrecer una visión alternativa en la que lo que resalte sea el carácter precisamente reiterativo de ciertas experiencias religiosas, el retorno a (o de) una forma religiosa anterior y dar así valor a teorias sobre la repetición, la reiteración y el eterno retorno que los antropólogos (a diferencia de los filósofos e historiadores de la religión inspirados por Nietzsche y Kierkagaard o por la fenomenología de Mircea Eliade) hemos abandonado, tal vez no sin cierta precipitación ${ }^{4}$. También pretendo continuar con mi reivindicación, ya atávica, del trabajo del filósofo y antropólogo Lucien Lévy-Bruhl, cuya fórmula platónica "mímesis=méthexis", escrita en griego en sus póstumos Cuadernos (publicados en 1949, diez años después de su muerte), me fascina y cuya significación intento explorar en este y otros textos.

Empecemos por la experiencia pentecostal, paradigma de los "nuevos" movimientos religiosos africanos y de la ruptura que, según muchos autores, tales movimientos representan vis-à-vis la tradición religiosa y las estructuras sociales. El Pentecostés "original", recordemos, fue el día en que los doce discípulos de Jesús se encontraban reunidos, cincuenta días después de la celebración de la Pascua judaica. Estaban desesperados: el maestro les había abandonado. ¿Cómo podían ellos transmitir el mensaje que éste les había dejado? Y ¿de qué serviría el mensaje sin el maestro? Permítanme ser radicalmente herético en relación al "mensaje" cristiano: estrictamente hablando, Jesús no traía ningún mensaje. No era una botella con un papelito en el cual alguien hubiera escrito "SOS". Jesús no tenía, sino que era un mensaje. El mensaje era todo él: su persona, su cuerpo, su pelo, sus pies, su sudor, su olor, su aliento, su voz, por supuesto su sangre, en definitiva su presencia. 0 , para resumirlo con la palabra mágica, su "carisma”. Curaba (e incluso resucitaba muertos) simplemente imponiendo las manos sobre el sufridor.

Ellos, los discípulos, lo sabían porque lo habían visto. ¿Pero cómo podían explicar todo esto a otra gente? ¿Quién les creería? Y ¿de qué serviría explicarlo, si de lo que se trataba era de la desaparición del maestro y por tanto de la imposibilidad de continuar esta acción milagrosa? Para dibujar un anacrónico Wittgenstein en el cuadro pentecostal: ¿De qué servía hablar de ello, si no se podía mostrar? El incipiente "cristianismo" (por usar una palabra muy posterior) corría el riesgo de tornarse pura mitología: un relato más o menos fantasioso sobre un tipo extra-ordinario, pero que ya no estaba entre nosotros.

Pero hete aquí que, como nos cuentan los Hechos de los Apóstoles, en plena reunión melancólica el Espíritu Santo cae sobre los apóstoles, como lenguas de fuego lanzadas desde el cielo. Hablan en lenguas,

3. Véanse Meyer, B. (1998); Robbins, J. (2007); Engelke, M. (2004); Sarró, R. y R. Blanes (2009); Marshall (2009). Para una crítica de la llamada “antropología del cristianismo”, véase Hann, C (2007) y Hann, C. (2012).

4. Como muestran Reinhardt Koselleck y otros filósofos de la temporalidad, no hay en realidad incompatibilidad entre modelos históricos lineales y modelos circulares: diferentes modelos pueden invocarse alternativamente (Koselleck, R. [2001]). Esta alternancia es el tema que estoy desarrollando en un artículo paralelo sobre la temporalidad y la escatológía en la teología kimbanguista. 
se sienten poseídos por el mismo espíritu (el mismo: conviene insistir en esta identificación, que colapsa la temporalidad) que poseía Jesucristo, y de repente pueden hacer, ellos, las acciones que el maestro hacía: para volver a Wittgenstein, ya no hace falta que hablen, ahora pueden mostrarlo, y al mostrarlo pueden continuar la acción (y no sólo repetir el recuerdo proposicional, más o menos mitificado) de la persona desaparecida: la historia del cristianismo, que se había detenido, encallada en la tristeza los apóstoles, puede retomarse y continuar. La presencia de ellos se vuelve sinónima de, o consubstancial a, la presencia real de Jesús. Curan, como nos aseguran los Hechos, "en nombre de Jesús", y probablemente muchos de aquellos frente a quienes se presentan piensen que, de hecho, es el propio Jesús el que los está curando o bendiciendo. En el momento de la posesión pentecostal, la copia (el evangelista) se convierte en el modelo ejemplar (Jesús). Exactamente como dijo Lévy-Bruhl: la mímesis, o sea, la imitación, conduce a la méthexis, o sea, la participación, la consubstancialidad.

Pero la muerte se impone sobre la temporalidad participativa. Los compañeros de Jesús, que continuaron su acción mientras vivían, también murieron. El carisma que los poseía, el Espíritu Santo, ya no podía curar por la mera presencia. El "cristianismo” comenzó a nacer a medida que se iba reforzando el recuerdo y desvaneciendo la presencia. Surgió el "mensaje": un conocimiento explícito, verbal, semántico $\mathrm{y}$ proposicional sobre lo que hizo y dijo Jesús. Un mensaje atractivo para muchos, por supuesto, pero no será preciso una do- sis demasiado grande de mala fe para admitir que, por sí solo, es bastante incapaz de curar cegueras, o de resucitar muertos. Durante muchos siglos, la capacidad de ser poseído por el Santo Espíritu no fue aceptada por la iglesia (ni católica ni protestante, ni occidental ni oriental). Era algo que les pasó a los discípulos de Jesús, como recordamos todos los años el día del Pentecostés (recordamos la historia, sin revivirla), pero desde entonces no ha vuelto a pasar y no puede volver a pasar. Si alguien se siente poseído, es más probable que lo sea por el demonio que por el Espíritu Santo. El éxtasis es sospechoso y solo un buen discernimiento puede establecer si es divino o diabólico. En caso de duda, mejor alejarse...

Pero la rutinización o burocratización del carisma tiene sus límites y con el tiempo (tiempo en sentido de duración, el duro pasar de un día tras otro que el evento profético tiende a abolir, como sugirió el filósofo tomista e islamólogo Louis Gardet en un inspirado texto sobre la temporalidad profética ${ }^{5}$ ) conduce a un anquilosamiento y a una situación de melancolía similar a la de los apóstoles el día de Pentecostés original. ¿Podemos revivir esa presencia espiritual de Jesús? Desde fines del siglo XIX nos encontramos en el seno del cristianismo con un hecho religioso que va en sentido contrario a veinte siglos de "dura" duración cristiana. Tras veinte siglos de rutinización teológica, surgen a finales del siglo XIX iglesias (sobre todo en las lejanías periféricas de las praderas norteamericanas lejos del control hermenéutico de teólogos católicos o luteranos) en que se vuelve a vivir el fenómeno de la posesión del Espíritu Santo. Son llamadas iglesias pentecostales (aho-

5. Véase Gardet, L. (1979). Para un análisis antropológico del “momento profético”, a la luz de la antropología del acontecimiento, me remito a los dos artículos clásicos de Edwin Ardener "Some outstanding problems in the analysis of events" y "The voice of prophecy”, ambos incluidos en Ardener (1989). 
ra denominadas "neo-pentecostales", porque hubo un periodo a mediados del siglo XX en que desaparecieron antes de volver con fuerza a finales del siglo XX). En estas nuevas (¿o muy antiguas?) religiosidades cristianas (primero vinculadas sólo al entorno protestante, pero hoy también hay un cierto "pentecostalismo" en el seno del catolicismo) el individuo experimenta la posesión del Espíritu Santo. Veinte siglos de historia se colapsan para hacer resurgir un cristianismo primitivo de posesión y de milagros. Mostrar vuelve a ser más importante que hablar. Ir a misa vuelve a ser una actividad extática (si bien la sospecha diabólica no desaparece del todo). Pese a la importancia de la Biblia en el protestantismo (más presente en el culto y en la vida privada del religioso que en el catolicismo), muchos movimientos pentecostales incluso le retiran importancia, porque la Biblia, el relato, es una mediación, y el individuo no necesita de mediaciones para vivir en comunión y participación con la presencia divina ${ }^{6}$.

Visto en retrospectiva, podríamos argumentar que el neo-pentecostalismo de hoy en día "copia" el pentecostalismo de finales del siglo XIX. El pentecostalismo de finales del siglo XIX copiaba el Pentecostés del siglo I. El Pentecostés del siglo I copiaba el poder carismático de Jesús (Jesús no copiaba nada, porque es el "ejemplo" original y absoluto). La copia se nos aparece en la conciencia, casi espontáneamente, como una hipótesis plausible. Así, cuando yo explico a muchos colegas que en la religión kimbanguista (movimiento religioso centro africano que surgió a partir de la actividad profética de Simon Kimbangu y especialmente presente hoy en los dos Congos y en Angola) existe hoy posesión espiritual (cosa que no acontecía en décadas anteriores), muchos me responden que esto debe de ser una "influencia" de las iglesias pentecostales que abundan hoy en el Congo y en Angola. 0 sea: el kimbanguismo, según esta hipótesis, está copiando al pentecostalismo circundante. Yo creo que la hipótesis es falsa, aunque entiendo que sea sugerente (yo tengo otras, si bien no será éste el mejor contexto para discutirlas). El propio profeta, Simon Kimbangu (nacido en 1887), temblaba y se sentía poseído (posiblemente por el Espíritu Santo del que le hablaron en la misión baptista, en la que fue catequista) ya antes de 1921, según consta en los archivos, o sea mucho antes de que Kinshasa, Brazzaville o Luanda se tornaran el espectáculo neo-pentecostal que son hoy en día.

La copia, en nuestra epistemología, nos aleja del modelo. Pero precisamente la fuerza del pentecostalismo y de la posesión por el Espiritu Santo radica en que en estos fenómenos la copia no es lo que nos aleja del modelo, sino lo que nos acerca a él. No es como el dibujo de la cama según Platón (que es una copia de la cama material, copia a su vez de la cama ideal) o como la fotocopia de una fotocopia de una fotocopia que cada vez va quedando más difuminada y borrosa, sino una copia que cada vez más nos devuelve al origen: a la presencia espiritual y a la fuerza curativa, inexplicable y numinosa, de Jesús?

6. Véase la penetrante monografía de M. Engelke (2007), sobre la ambivalencia de la mediación bíblica en un iglesia apostólica de Zimbabwe.

7. Conviene aquí recordar que la idea transgresora de que la copia puede ser más efectiva que el original atraviesa una gran parte de la reflexión sobre la copia, desde la filosófica de Deleuze hasta las reflexiones en la cultura popular como las que vehiculan el magistral relato breve de Henry James "The real thing" (en James 1893) o la no menos magistral película de A. Kiarostami “Copia certificada” (2010). Pero lo que 
Paradoja de la historia cristiana: para seguir adelante, la historia tiene que volver repetidamente al origen, como si nos fuera saliendo la famosa tarjetilla del juego del Monopoly: "vuelva la casilla de salida". Y volvemos (o algunos vuelven) y entonces se retoma con fuerza la historia, y nuevos misioneros se van a África a explicar la gloria de Jesús y el poder del Espíritu Santo. (De hecho, una gran parte de misión cristiana en el tercer mundo, y me atrevería a decir que también en Occidente, es de corte pentecostal).

Vayamos ahora a Guinea-Bissau. Durante los últimos seis años he estado estudiando, en este pequeño país de África occidental y en colaboración con Marina Temudo (que inició sus estudios entre los balantas de Guinea-Bissau ya en 1993), un movimiento profético llamado kyangyang. Este movimiento surgió en 1984 cuando Ntombikte, una joven mujer de extracción campesina y analfabeta (ni siquiera la lingua franca kriol hablaba, a diferencia de otros muchos campesinos guineanos), fue poseída por Dios y empezó a dictar mandamientos divinos a los agricultores de la etnia balanta, a la que pertenecía (escribo en pretérito porque Ntombikte, a quien entrevistamos por última vez en 2008, falleció en 2013). Será importante señalar que los balantas eran un pueblo animista bastante marginalizado en el imaginario nacional de esa época, sobre todo después del golpe de estado de 1980 orquestrado por Nino Vieira, quien, a pesar de haber contado con el apoyo de militares balantas, fue gradualmente retirándolos del poder. A mediados de la década de los 1980 resurgió un viejo estereotipo colonial que veía a los animistas balantas como a los miembros más “atrasados" del territorio nacional. A pesar de la importancia que habían tenido como aguerridos soldados rebeldes en la creación del país independiente en las dos décadas anteriores, fueron brutalmente apartados del estado y de las jefaturas del ejército y obligados a refugiarse en los márgenes agrícolas. (Hoy, aunque Guinea-Bissau haya tenido un presidente de la república de origen balanta a inicios de la década de 2000, continúan bastante marginalizados). Y fue en los márgenes donde surgió el movimiento extático y profético iniciado por Ntombikte, que pronto reunió a miles de seguidores (de todos los sexos y edades) a su alrededor, como documentaron en su momento estudiosos que lo presenciaron y que escribieron sobre ello, como el sociólogo guineano Carlos Cardoso, el antropólogo holandés Roy van der Drift o la historiadora de las religiones sueca Inger Callewaert ${ }^{8}$.

El kyangyang es un movimiento fuertemente mimético. Sus seguidores, cuando están poseídos (normalmente por un ancestro, aunque algunos, como la profeta que dio origen al movimiento, aseguran estar poseídos por Nhala, el dios creador de la cosmología balanta), copian el comportamiento de los cristianos y - sobre todo de los musulmanes que los rodean: rezan

me interesa aquí es insistir en lo engañoso de ver ciertos movimientos sociales como "copia" sin atender a las profundas vivencias que los acompañan, vivencias que colapsan (como lo hace, a otro nivel, la noción cristiana del pecado original) precisamente la distinción entre lo original y la copia y nos obligan a reflexionar sobre la profunda autenticidad de toda experiencia humana.

8. Cardoso, C. (1990); Van der Drif, R. (1992), pp. 230-240; Callewaert, I. (2000). Para una contextualización del movimiento, véanse también Temudo, M. (2009) y de Jong, J. T. y R. Reis (2010). 
como ellos, se visten como ellos, construyen templos como ellos, y, aunque analfabetos, escriben y leen como ellos en glosografías profusamente imaginativas. Por eso los musulmanes y cristianos en Guinea-Bissau se rien de ellos y llaman a su movimiento "religión de copia", "religión de broma" o, usando un concepto de la propia lengua balanta, kyangyang, vocablo que significa "sombra" (les guste o no, es así como el movimiento se conoce entre los estudiosos, si bien conviene insistir en que los miembros del movimiento raramente lo usan: ellos prefieren autodenominarse "hijos de Nhala"). 0 sea, lo ven como una sombra sin alma, que copia el "modelo" (esto es, el buen musulmán, el buen cristiano del espacio público guineano) sin otro efecto que la imitación vacía, como la que haría un mono. Recordemos el genial, si bien éticamente algo problemático, fragmento de la película de Walt Disney "El Libro de la Selva” (1967) en que los monos cantan a Mowgli, a ritmo de jazz (cabe preguntarse ¿por qué se escogió un estilo propio de negros afro-americanos para musicalizar ese esfuerzo mimético de los monos en la jungla?) "I wanna be like you”. Claro que ellos, los monos, no pueden ser como nosotros, los humanos, porque hay una barrera infranqueable entre monos y humanos. Pero desgraciadamente, este fragmento, con el que tantos crecimos, ilustra muy bien nuestra epistemología de la copia: la copia como algo secundario. Mowgli 1, Monos 0.

Mientras que la metáfora de este resultado final tan arrollador para los humanos se aplica perfectamente a las imitaciones (y limitaciones) de los monos, cuya capacidad de aprendizaje, por fenomenal que sea, no puede hacerles traspasar barreras biológicas, difícilmente se aplicará a la de los balantas $\mathrm{u}$ otros humanos. $\mathrm{Y}$ es que los humanos, a fuerza de copiarnos unos a otros, llegamos a transformarnos en otra cosa. Tenemos que dejar de pensar en la copia como un mero esfuerzo sin contenido, como hacen los musulmanes y cristianos guineanos en relación al kyangyang, o nosotros en relación a tantos movimientos “miméticos". Volvamos a Lévy-Bruhl: La mímesis, nos asegura, es lo mismo que la méthexis. ¿No sería más productivo, propongo, tomar en serio la fórmula y hablar menos de movimientos miméticos y más de movimientos methéxicos, o sea, participativos? En cierta forma, esto es lo que propone James Ferguson en su artículo de 2002 "Of mimecry and membership: Africans and the new world society" (artículo reimpreso en un libro de ensayos de 2006 cuyo título es, casualmente, Global Shadows, si bien Ferguson no habla de las "sombras" de Guinea-Bissau a las que hago alusión aquí). Intentando combatir la excesiva fascinación por la mímesis que ha atravesado gran parte de la literatura africanista ${ }^{9}$, Ferguson insiste en que si los movimientos religiosos (o sociales) son miméticos es precisamente porque están vehiculando una exigencia a una membership, a la participación política y cívica de la que se excluye a sus miembros, y porque son mecanismos de inclusión en ese espacio público (o, por lo menos, si no de directa inclusión, sí son, parafrasearía yo, mecanismos de aprendizaje cívico). Podría argumentarse, lo acepto, que algo parecido proponía Taussig en su influyente libro Mimesis and Alterity ya en 1993, libro que, si bien con una inspira-

9. Cf., por ejemplo, Kramer, F. (1993) o Stoller, P. (1995). 
ción más benjaminiana que lévy-bruhliana, propone una tesis semejante a la que llegamos quienes seguimos a Lévy-Bruhl: la mímesis, había sugerido Walter Benjamin, conduce a la transformación del sujeto y a la identificación plena con lo imitado. Puede parecer, pues, que esté reinventando la rueda, pero que conste que soy plenamente consciente de ello. Más acertado sería decir que, lejos de querer reinventarla, sólo pretendo hacerla rodar.

$\mathrm{Al}$ copiar a sus vecinos monoteístas, los kyangyang están poseídos, y la oración que hacen cuando rezan (normalmente lo hacen en glosolalia, o sea, "hablando en lenguas”, incompresiblemente) no es una imitación de la oración cristiana o musulmana, o una repetición de fórmulas lingüísticas “vacías”, sino la exteriorización de una vivencia inenarrable. Un kyangyang que Marina y yo entrevistamos a finales de 2011 nos lo dijo así: Le pedimos si podía leer un texto escrito en glosografía (escritura individual, inventada por los kyangyang en plena posesión) escrito por otro kyangyang algunos años antes y que nosotros habíamos fotografiado e imprimido. Dijo que sí, que sin problema. $\mathrm{Al}$ tomarlo entres sus manos y comenzar a "leerlo" (si es que el verbo "leer" puede aplicarse a la actividad mística que realizó, tal vez más semejante a contemplar un mandala que a extraer información de un texto), entró en un estado de espíritu claramente alterado. Con su dedo y con sus ojos recorrió el texto (de hecho, era más bien una mezcla de dibujo y de texto), haciendo unos movimientos de cabeza temblorosos y repetitivos. Al terminar de leerlo nos lo devolvió, con una sonrisa de satisfacción extática, y volviendo a su yo controlado y social dijo: “Gracias”.
Y entonces, - le pregunté -, ¿qué dice este texto?

Se me quedó mirando. "Yo lo puedo leer" me dijo -; "pero no te puedo explicar lo que dice".

Sin duda estábamos frente a alguien que acababa de tener una experiencia religiosa profunda e intransferible. Pero sin duda, también, a ojos de la mayor parte de habitantes del espacio público guineano, el musulmán capaz de explicar el Qu'ran, o el cristiano capaz de explicar la Biblia es más, o mejor, religioso que este campesino kyangyang y sus silencios wittgensteinianos, si bien éstos, y sus temblores, tal vez sean más similares a la vivencia mística de Mohammed en el desierto o de Jesús en la montaña que el discurso ético e histórico de los ulema, obispos y pastores de Bissau. Pero para la conciencia moderna la copia es siempre fea. Son sombras, puras sombras. No solo para el buen musulmán o cristiano guineano. También tengo colegas que se preguntan por qué pierdo el tiempo estudiando algo tan sincrético como el kyangyang en vez de estudiar fenómenos religiosos más auténticamente africanos, como ritos de paso, mascaradas o sacrificios.

Son copias, sí (tal vez como los ritos de paso, las mascaradas y los sacrificios, que sólo son "auténticos" dentro de un marco hermenéutico que opone lo auténticamente africano a los espurios, pero que en su historicidad interna deben de haberse sometido, en un momento u otro, a dinámicas de copia, como cualquier otra obra humana). Propongo que la copia no sea vista como un resultado, sino una capacidad, una potencia. Sin la potencia humana para copiar ¿habría cultura humana? ¿Sin la capacidad humana de colapsar, e incluso revertir, la historia 
repitiendo el evento original, habría, realmente, historia? El movimiento kyangyang se sitúa, desde la óptica (o panóptica) del observador, en el final de una línea temporal cuasi teleológica, ofreciendo un ejemplo de "innovación" religiosa o aun de "nuevo movimiento religioso" en Guinea-Bissau, de forma semejante a como, en el timescape hegemónico guineano ${ }^{10}$, el balanta animista se sitúa en un momento de evolución histórica "anterior" al alcanzado por el criollo católico o el mandinga musulmán. Pero éstas son categorizaciones externas. En la intimidad de lo vivido, el kyangyang ofrece la repetición del tipo de experiencia extática que dio origen a las "grandes religiones". Estudiar este tipo de innovaciones bajo el signo de la copia y de la mímesis puede ser equívoco y hacernos perder lo que, para el sujeto religioso, es lo más importante. Hacerlo bajo el signo de la méthexis y de la potencia puede permitirnos comprender que "hacer historia" es siempre re-sumergirse en el fango de los orígenes, y que la historia se teje en colectividad, siendo muy a menudo las periferias las que refrescan, con su viva imaginación, el pesado devenir histórico y tornan más liviana la duración de la que nos hablaba Louis Gardet. Mezclando, con el debido respeto, al foucaultiano Ferguson con el platónico Lévy-Bruhl, me gustaría argumentar que si ha habido tantos profetas "miméticos" en situaciones coloniales no es porque los profetas quieran sustraer de la historia a sus seguidores, resguardándolos en "enclaves de pureza" (para usar el bello concepto con que Mary Douglas, en In the Wilderness [2001], captura los origenes de ciertas comunidades religiosas) heterotó- picos y heterocrónicos, sino precisamente porque quieren que ésta, la historia, acontezca. Para todos. Como acontece en el centro, así acontecerá también en la periferia. Como acontece en la periferia, así acontecerá también en el centro. Para resumirlo con la famosísima parábola de Simon Kimbangu cuando fue detenido, en la alejada aldea congoleña de N'kamba, por las autoridades belgas en 1921 (¿parábola que copió, tal vez, de alguna pronunciada por Jesucristo, que él aprendiera de los misioneros baptistas?): "El negro será blanco y el blanco será negro"11. Somos todos iguales. ¿Acaso no era éste el mensaje?

\section{REFERÊNCIAS}

ARDENER, E. The Voice and Prophecy and other Essays. Oxford: Blackwell, 1989.

BORGES, J. L. El tiempo circular. In: . Historia de la eternidad. Buenos Aires: Emecé, 1953, p. 91.

CALLEWAERT, I. The Birth of Religion among the Balanta of Guinea Bissau. Lund: Univeristy of Lund Press, 2000.

CARDOSO, C. Ki-Yang-Yang: Uma nova religião dos Balantas? Soronda: Revisa de Estudos Guineeneses, n. 10, p. 3-15, 1990.

DOUGLAS, M. In the Wilderness: The Doctrine of Defilement in the Book of Numbers. Oxford: Oxford Unviersity Press, 2001.

ENGELKE, M. Discontinuity and the discourses of conversion. Journal of Religion in Africa, 34, n. 1-2, p. 82-109, 2004.

FERGUSON, J. Of mimecry and membership: Africans and the new world society. Cultural Anthropology, 17, n. 4, p. 551-569, 2002.

10. Tomo prestado el concepto de timescape, con una ligera modificación de su significado, a Tom Otto (2013).

11. Para un análisis de esta provocadora parábola kimbanguista, véase Sarró, R. y A. Mélice (2014). 
GARDET, L. (1979) El profeta y el tiempo. In: RICOEUR, P. et al. (Orgs.) El tiempo y las filosofías. Salamanca: Sígueme, 1979, p. 232-246.

HANN, C. The anthropology of Christianity per se. Archives Européennes de Sociologie, 48, n. 3, p. 383-410, 2007.

- Personhood, Christianity, Modernity. Anthropology of this Century, n. 3, 2012.

JAMES, $\mathrm{H}$. The real thing. In: The Real Thing, and Other Stories. New York: MacMillan, 1893, p. 1-44.

JONG, J. T.; REIS, R. Kiyang-yang, a West-African postwar idiom of distress. Culture, Medicine and Psychiatry, n. 34, p. 301-321, 2010.

KOSELLECK, R. Sobre la antropología de las experiencias del tiempo histórico. In: Los estratos del tiempo: estudios sobre la historia. Tradução de D. Innerarity. Barcelona: Paidós, 2001, p. 35-114.

KRAMER, F. The Red Fez: Art and Spirit Possession in Africa. London; New York: Verso, 1993.

LEWIS, I. Ecstatic Religion: A Study of Shamanism and Spirit Possession. London: Penguin Books, 1971.

MARSHALL, R. Political Spiritualities: The Pentecostal Revolution in Nigeria. Chicago: University of Chicago Press, 2009.

MEYER, B. Make a with the past: memory and postcolonial modernity in Ghanaian Pentecostal discourse. In: WERBNER. R (Org.) Memory and the Postcolony: African Anthropology and the Critique of Power. London: Zed Books, 1998, p. 182-208.

OTTO, T. Times of the other: the temporalities of ethnographic fieldwork. Social Analysis, 57, n. 1, p. 64-79, 2013.

ROBBINS, J. Continuity thinking and the problem of Christian culture: belief, time and the Anthropology of Christianity. Current Anthropology, n. 48, p. 5-38, 2007.
SARRÓ, R.; BLANES, R. A prophetic diaspora: moving religion across the Lusophone Atlantic. African Diaspora, n. 2, p. 52-72, 2009.

SARRO, R. ; MELICE, A. Le renversement du monde dans le message de Simon Kimbangu. In: M'BOKOLO, E.; SABAKINU, K. (Orgs.) Simon Kimbangu, le prophète de la libération de l'homme noir. Paris: L'Harmattan, n. 2, 2014, p. 21-26.

STOLLER, P. Embodying Colonial Memories: Spirit Possession, Power, and the Hauka in West Africa. London: Routledge, 1995.

TAUSSIG, M. Mimesis and Alterity: A Particular History of the Senses. New York: Routledge, 1993.

TEMUD0, M. From the margins of the state to the presidential palace: Balanta of Guinea- Bissau. African Studies Review, 52, n. 2, p. 47-67, 2009.

VAN der DRIF, R. (1992) Arbeid en Alcohol. Leiden: CSNW Publications, 1992. 
RESUMO

Este texto pretende contrariar la tendencia a ver ciertas manifestaciones religiosas "nuevas" (en especial los movimientos proféticos africanos) como mecanismos de "ruptura total con el pasado" o como ejemplos de "innovación" cultural, y ofrecer una visión alternativa en la que lo que resalte sea el carácter reiterativo de ciertas experiencias religiosas, el retorno a (o de) una forma religiosa anterior y dar así valor a teorías sobre la repetición, la reiteración y la importancia del presente vivido, que aparece como olvidado en la literatura contemporánea, en comparación con el valor que tanto el pasado recordado como el futuro esperado reciben en la antropología de la religión.

\section{PALAVRAS-CHAVE}

Methexis (participación), presente, ruptura, repetición, Lévy-Bruhl, Balanta, GuineaBissau

\section{ABSTRACT}

This paper intends to counteract the tendency to see certain "new" religious manifestations (specially the African prophetic movements) as mechanisms of "total disruption with the past" or as examples of cultural "innovation", and to offer an alternative version in which what is highlighted is the reiterative character of certain religious experiences, the return to (or of) a previous religious form and then give value to theories on the repetition, the reiteration and the importance of the lived present, which appears as forgotten in the contemporary literature, compared to the value that both the reminded past and the expected future receive in the anthropology of religion.

\section{KEYWORDS}

Methexis (participation), present, disruption, repetition, Lévy-Bruhl, Balanta, Guinea-Bissau

Recebido em: 26.03.18

Aprovado em: 13.06.18 